\title{
Valorization of waste oil palm (Elaeis guineensis Jacq.) biomass through furfurylation
}

\begin{abstract}
Malaysia is the biggest producer of palm oil in the world. The production generates large amounts of waste trunks which should be considered a valuable bio-feedstock rather than waste. An approach for valorization of waste oil palm biomass $\ddot{i}$ especially that of low density hardly applicable in industry $\ddot{i}$ through furfurylation was investigated. Furfuryl alcohol treatment resulted in great improvement in the properties of the material: $200 \%$ density gain, water absorption and thickness swelling reduced by $50 \%$ and $74 \%$, respectively, hardness increased by $400 \%$, as well as 3.5-fold and 7.4-fold increase, respectively, in bending strength and modulus of elasticity was observed. Alternations in physical and mechanical properties of oil palm trunk combined with aesthetic changes due to material darkening may be considered an effective approach for conversion of waste biomass to novel materials of enhanced technical value.
\end{abstract}

Keyword: Oil palm; Elaeis guineensis; Furfuryl alcohol; Modification 